1

2

3

\title{
1 Numerical simulation of two-phase flow for sediment transport in the
} inner-surf and swash zones

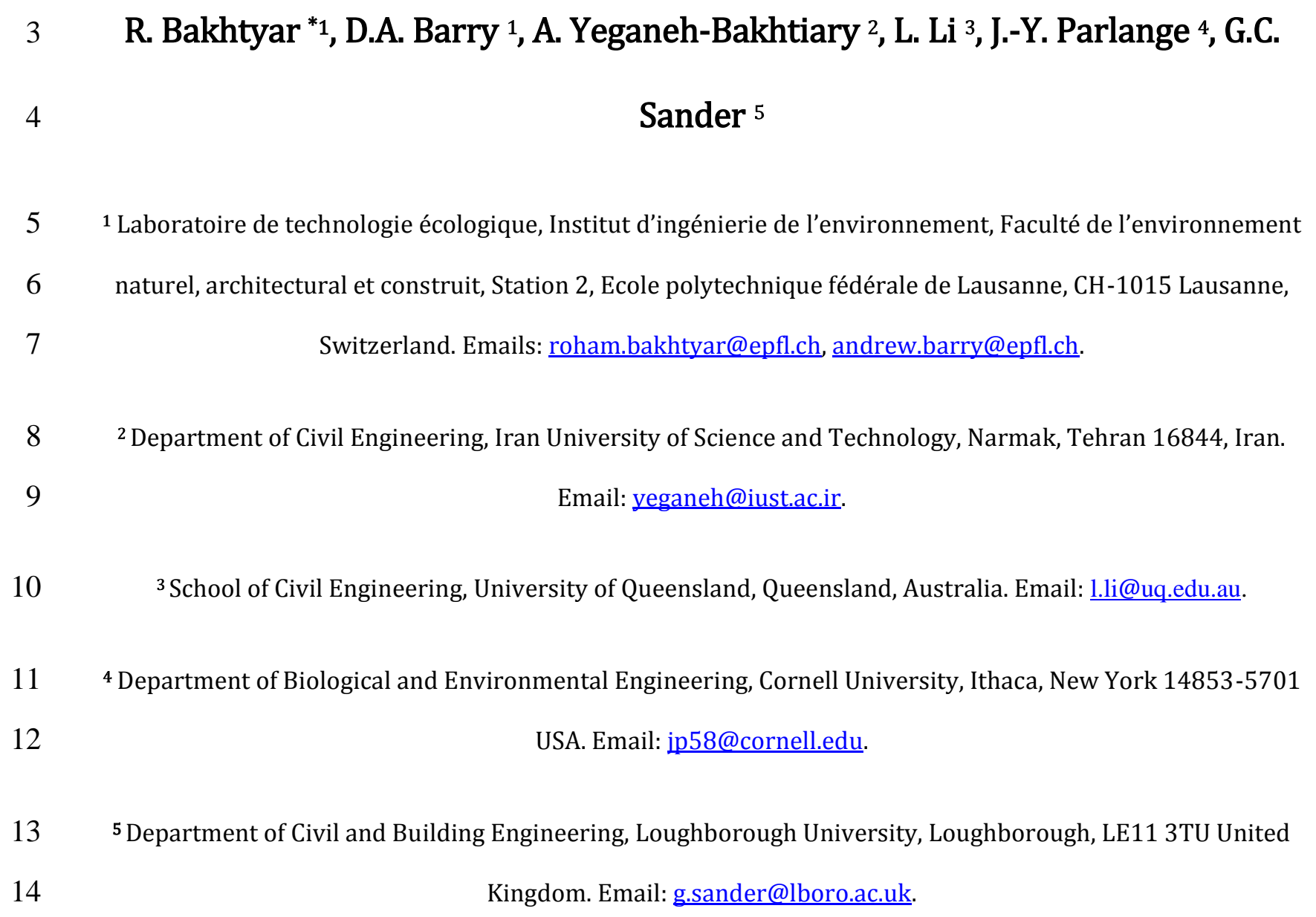
Kingdom. Email: g.sander@lboro.ac.uk.

15 Revision submitted to Advances in Water Resources, 11 December 2009

\footnotetext{
${ }^{*}$ Author to whom all correspondence should be addressed. Ph. +41 (21) 693-8087. Fax. +41 (21) 693-5670.
} 
17 A two-dimensional two-phase flow framework for fluid-sediment flow simulation in the surf 18 and swash zones was described. Propagation, breaking, uprush and backwash of waves on 19 sloping beaches were studied numerically with an emphasis on fluid hydrodynamics and 20 sediment transport characteristics. The model includes interactive fluid-solid forces and in21 tergranular stresses in the moving sediment layer. In the Euler-Euler approach adopted, two 22 phases were defined using the Navier-Stokes equations with interphase coupling for mo23 mentum conservation. The $k-\varepsilon$ closure model and Volume-Of-Fluid approach were used to 24 describe the turbulence and tracking of the free surface, respectively. Numerical simulations 25 explored incident wave conditions, specifically spilling and plunging breakers, on both dis26 sipative and intermediate beaches. It was found that the spatial variation of sediment con27 centration in the swash zone is asymmetric, while the temporal behavior is characterized by 28 maximum sediment concentrations at the start and end of the swash cycle. The numerical 29 results also indicated that the maximum turbulent kinetic energy and sediment flux occurs 30 near the wave breaking point. These predictions are in general agreement with previous ob31 servations, while the model describes the fluid and sediment phase characteristics in much 32 more detail than existing measurements. With direct quantifications of velocity, turbulent 33 kinetic energy, sediment concentration and flux, the model provides a useful approach to 34 improve mechanistic understanding of hydrodynamic and sediment transport in the near35 shore zone.

36 Keywords: Continuous phase; Euler-Euler coupling; Fluid-solid interaction; Momentum ex37 change; Nearshore zone; Particle-particle interaction; Wave breaking 
38 Abbreviations

\section{NLSWE}

Non-Linear Shallow Water Equation

Navier-Stokes

41 RANS

Reynolds-Averaged Navier-Stokes

42

SWL

Still Water Level

43 TDR

Turbulent Dissipation Rate

TKE

Turbulent Kinetic Energy

45 VOF

Volume Of Fluid 46

\section{Nomenclature}

maximum static sediment concentration

empirical constants

$[-]$

particle diameter 


\begin{tabular}{|c|c|c|}
\hline$F$ & fluid volume per cell volume & {$\left[\mathrm{L}^{3} \mathrm{~L}^{-3}\right]$} \\
\hline $\overrightarrow{\mathrm{g}}$ & gravitational acceleration & {$\left[\mathrm{LT}^{-2}\right]$} \\
\hline$h$ & flow depth & {$[\mathrm{L}]$} \\
\hline$H$ & height of incident waves & {$[\mathrm{L}]$} \\
\hline$k$ & turbulent kinetic energy & {$\left[\mathrm{L}^{2} \mathrm{~T}^{-2}\right]$} \\
\hline $\overrightarrow{\mathrm{k}}$ & unit vector in the $z$ direction & {$[-]$} \\
\hline$L$ & wavelength of incident waves & {$[\mathrm{L}]$} \\
\hline$P$ & pressure & {$\left[\mathrm{ML}^{-1} \mathrm{~T}^{-2}\right]$} \\
\hline$t$ & time & {$[\mathrm{T}]$} \\
\hline$T$ & wave period & {$[\mathrm{T}]$} \\
\hline $\overrightarrow{\overrightarrow{\mathrm{T}}}_{f}$ & fluid phase stress tensor & {$\left[\mathrm{ML}^{-1} \mathrm{~T}^{-2}\right]$} \\
\hline $\overrightarrow{\vec{T}}_{s}$ & sediment phase stress tensor & {$\left[\mathrm{ML}^{-1} \mathrm{~T}^{-2}\right]$} \\
\hline$\vec{U}, \vec{V}$ & fluid and sediment vector velocities & {$\left[\mathrm{LT}^{-1}\right]$} \\
\hline$U_{x}, U_{z}$ & fluid velocities in the $(x, z)$ directions & {$\left[\mathrm{LT}^{-1}\right]$} \\
\hline$V_{x}, V_{z}$ & sediment velocities in the $(x, Z)$ directions & {$\left[\mathrm{LT}^{-1}\right]$} \\
\hline
\end{tabular}




\begin{tabular}{|c|c|c|}
\hline$X, Z$ & horizontal and vertical coordinates & {$[\mathrm{L}]$} \\
\hline Greek & & \\
\hline$\beta$ & beach slope & {$[-]$} \\
\hline$\xi$ & surf scaling parameter & {$[-]$} \\
\hline$\zeta_{0}$ & surf similarity parameter & {$[-]$} \\
\hline$\rho_{f}, \rho_{s}$ & fluid and sediment densities, respectively & {$\left[\mathrm{ML}^{-3}\right]$} \\
\hline$v$ & kinematic viscosity & {$\left[\mathrm{L}^{2} \mathrm{~T}^{-1}\right]$} \\
\hline$v_{t}$ & eddy viscosity & {$\left[\mathrm{L}^{2} \mathrm{~T}^{-1}\right]$} \\
\hline$\varepsilon$ & turbulent dissipation rate & {$\left[\mathrm{L}^{2} \mathrm{~T}^{-3}\right]$} \\
\hline$\omega$ & angular frequency & {$\left[\mathrm{T}^{-1}\right]$} \\
\hline$\varphi$ & angle of repose & {$[-]$} \\
\hline Subscripts & & \\
\hline 0 & deep water quantity & \\
\hline$b$ & breaking point value & \\
\hline Symbols & & \\
\hline$\nabla \equiv(\partial / \partial x, \partial / \partial z)$ & gradient vector & {$\left[\mathrm{L}^{-1}\right]$} \\
\hline
\end{tabular}


84

6

85

\section{[T-1]}

\section{Introduction}

The nearshore area is usually defined as the region extending from the landward limit of the swash zone to the seaward limit of the surf zone where the incident waves start to break as they approach the shore. In this zone, a large range of frequencies and types of fluid motions can be found, including short and long waves, currents, turbulence and vortices due to wave breaking, swash-swash interactions, boundary layer flow and interactions with sediments [34].

The majority of littoral sediments are transported within the surf and swash zones [7]. In coastal engineering, the quantification of nearshore sediment transport and the response of the coast to this process is a prerequisite for the design and planning of any coastal development. However, this task is challenging because of, amongst other factors, the highly turbulent flow nature in this nearshore zone. dynamics of fluid-sediment mixtures. If the bottom shear stress is low, the hydrodynamics are dominated by fluid-particle interactions. However, high bottom shear stress in the nearshore zone induces intense sediment transport especially near the bed, and a hyperconcentrated layer of moving sediments occurs. In this moving layer, interparticle collisions become significantly frequent and bring another important mechanism to the hydrodynamics, viz. particle-particle interactions. 
2

3

The significance and importance of wave breaking in nearshore area has provided the impetus for numerous investigations (e.g., [4,46-48]). However, field experimentation is challenging due to the difficulty and expense in deploying equipment, obtaining robust data and the variability of meteorological conditions. These difficulties have persuaded researchers to seek more and more assistance from numerical modeling to guide experimental design. In parallel to this, developments in computational hardware and numerical solution methods have driven the popularity of numerical modeling of wave breaking and related processes in recent years.

Improved modeling approaches need to resolve appropriately the temporal and spatial phase variations of the fluid and sediment flow characteristics. Uprush and backwash motions in the nearshore zone are characterized by high particle concentrations as well as variation of periodic shear stresses. Overall, model-based numerical investigations into the influence of nearshore sediment transport on beach morphology are few in number and tend to include many over-simplifications. Such models are typically based on time-averaged behaviors and hence are not suitable for the prediction of velocity and concentrations that undergo marked temporal variations. Even the more sophisticated mathematical models of sediment transport and oscillatory flows in the surf and swash zones are commonly based on the assumption that the dynamics of the grain and fluid mixtures are similar to single-phase fluid dynamics [39], and so they are usually appropriate only for low sediment concentrations [49].

The main approaches and models for nearshore sediment transport can be summarized as follows: (i) parametric and empirical models [28]; (ii) process-based numerical models 
[8]; and (iii) two-phase flow models [9]. Predictions of both empirical and process-based models in the nearshore zone especially near the breaking point are not accurate. The nearshore zone is driven by relatively high-energy hydrodynamics. Rather than a single phase, it is more realistic to consider sediment transport in this zone as consisting of two-phase mixtures comprised of sediment particles (sediment phase) and a fluid phase. An important fact that must be taken into account by the model is the momentum exchange between the two phases. This exchange arises because, in general, the two phases do not travel at the same velocity. This approach allows for direct modeling of the main mechanisms driving nearshore hydrodynamics, i.e., intergranular stresses and interaction between fluid and sediments.

Not surprisingly then, several two-phase flow models have been reported for simulations of sediment transport. Asano [2] presented one such model based on the approach of the Kobayashi and Seo [26], in which the vertical velocity of particles was approximated by empirical relations. Ono et al. [41] devised a model, which assumed the same horizontal velocity for the fluid and the particles. Gotoh and Sakai [15] presented a numerical model for sediment transport in the sheet flow regime and flow kinematics considering particleparticle interactions. Yeganeh-Bakhtiary et al. [49,50] presented a coupled Euler-Lagrange two-phase flow model for bed-load transport under high bottom shear conditions. Their model describes the bed-load transport as dynamically interdependent motions of individual sediment particles under the action of flow.

An important concept in the analysis of two-phase flows is how the phases are coupled. In general, this coupling is considered in the momentum conservation equations. There are 
two methods for coupling: (i) one-way coupling model wherein the fluid flow affects the sediment phase only, and (ii) two-way coupling wherein both phases affects each other. Calantoni et al. [9] used a VOF-NSE solver (RIPPLE model) to simulate the inner surf zone and swash zone flow with a 3-s wave period and wave height of $0.14 \mathrm{~m}$ on a planar, 1:10 sloping beach. The RIPPLE model was used to provide high-resolution predictions of the pressure gradient and fluid velocity in the horizontal and vertical directions, which were linked in a one-way coupling fashion to a Discrete Particle Model (DPM) [12] for motion of sediment grains. Dong and Zhang [11] presented a two-phase flow model capable of simulating fluid and particle motions in oscillatory sheet flows. Their eddy viscosity model is restricted and not suitable for modeling complex sheet flows, which are subjected to the influence of complex interactions between fluids and highly concentrated sediments under periodic motion.

The location of the moving sediments in the sheet flow layer is mainly governed by particle collisions and contacts, and is controlled by mechanisms different to the usual turbulencegenerated suspension.

Other two-phase modeling studies have been reported. Hsu et al. [20-22] considered unsteady oscillatory flow. Liu and Sato [31] simulated the net transport rate under combined wave/current conditions. Liu and Sato [32] then developed a sediment movement simulation under various asymmetric sheet flow conditions. Bakhtyar et al. $[5,6]$ developed an EulerEuler coupled two-phase flow model to simulate fluid-sediment oscillatory sheet flow. In their study, sediment and fluid velocity variations, concentration profiles, sediment flux and turbulence parameters of wave-generated sheet flow were examined numerically with a focus on sediment transport characteristics. 
As summarized in Table 1, existing mathematical models for simulating sediment transport in the surf and swash zones cannot describe satisfactorily sediment transport under wave breaking, nor do they model in detail the spatial and temporal evolution of sediment and fluid velocities. Eulerian two-phase flow theory has not yet been applied to modeling sediment transport in the nearshore zone.

The main purpose of this paper is to use the Euler-Euler two-phase flow modeling approach to investigate wave breaking and to describe the relevant hydrodynamic and sediment transport processes in the nearshore zone. We consider the temporal and spatial variations of sediment concentration, sediment and fluid velocity profiles, surf-swash zone hydrodynamics and turbulent flow. The model is based on Euler-Euler coupling of the governing equations for the sediment and fluid phases. Each phase is described via the NavierStokes equations with the interaction between the fluid and sediment phases described within momentum conservation equations [5]. A $k-\varepsilon$ turbulence closure model is employed to simulate the turbulence generation and translation processes. The free surface motion is modeled using the VOF technique. Incident waves are generated by internal source functions inside the computational domain. Then, propagation, deformation, uprush/backwash of the waves as well as the distribution of sediment characteristics are simulated and investigated in detail. The model has not been validated against experimental data since no suitable data sets are available currently. Rather, a series of numerical experiments were run to demonstrate the model's capacity to generate insights into nearshore processes.

Section 2 gives a description of the equations and boundary conditions for two-phase flow modeling. Hydrodynamic and sediment transport in the surf and swash zones are dis- 
cussed and compared through numerical experiments in $§ 3$. Finally, §4 draws conclusions based on the results discussed in $\S 3$.

\section{Mathematical formulation of the two-phase flow model}

Numerical results based on existing sediment transport models are very sensitive to the sediment transport formula used [7]. Two-phase flow modeling is capable of separately simulating the sediment and fluid phases in the nearshore zone, while coupling between them can be accomplished through the momentum transfer. In the Euler-Euler approach, the sediment phase is treated as a continuum, although it follows different constitutive laws from those of the clear water. This approach accounts well for fluid-sediment interactions although the fundamental characteristics of the sediment motion, which are probabilistic due to irregularity of interparticle collision, cannot be well expressed.

Bakhtyar et al. [5] developed a two-dimensional (cross-shore) two-phase flow model for the simulation of turbulence and sediment characteristics in oscillatory sheet flow conditions. The model is governed the Reynolds-Averaged Navier-Stokes (RANS) equations for both phases with a $k-\varepsilon$ turbulence closure model. The present study improves the previous model to explore its capability in simulating sediment transport under breaking waves in the surf and swash zones. Essential details of the model equations and their numerical solutions are described below. 
$7212 \quad$ Fluid phase hydrodynamics [5]

$$
\frac{\partial\left[(1-C) \rho_{f} \overrightarrow{\mathrm{U}}\right]}{\partial t}+\nabla \cdot\left[(1-C) \rho_{f} \overrightarrow{\mathrm{U}} \overrightarrow{\mathrm{U}}\right]=(1-C) \rho_{f} \overrightarrow{\mathrm{g}}-\nabla \cdot[(1-C) P]+\nabla \cdot \overrightarrow{\overrightarrow{\mathrm{T}}_{f}}-\overrightarrow{\mathrm{f}}_{i n},
$$

Sediment phase hydrodynamics [5]

$$
\begin{aligned}
& \frac{\partial\left(C \rho_{s}\right)}{\partial t}+\nabla \cdot\left(C \rho_{s} \overrightarrow{\mathrm{V}}\right)=0, \\
& \frac{\partial\left(C \rho_{s} \overrightarrow{\mathrm{V}}\right)}{\partial t}+\nabla \cdot\left(C \rho_{s} \overrightarrow{\mathrm{V}} \overrightarrow{\mathrm{V}}\right)=C \rho_{s} \overrightarrow{\mathrm{g}}-\nabla \cdot(C P)+\nabla \cdot \overrightarrow{\mathrm{T}}_{s}+\overrightarrow{\mathrm{f}}_{i n},
\end{aligned}
$$

Interphase forces $[12,37]$

$$
\begin{aligned}
& \overrightarrow{\mathbf{f}}_{i n}=\frac{3 C \rho_{f}}{4 d} C_{D}(\overrightarrow{\mathrm{U}}-\overrightarrow{\mathrm{V}})|\overrightarrow{\mathrm{U}}-\overrightarrow{\mathrm{V}}|+\frac{3 C \rho_{f}}{4 d} C_{L}|\overrightarrow{\mathrm{U}}-\overrightarrow{\mathrm{V}}| \nabla(\overrightarrow{\mathrm{U}}-\overrightarrow{\mathrm{V}}) \cdot \overrightarrow{\mathrm{k}} \\
& C_{D}=\left(\frac{24 v}{d|\overrightarrow{\mathrm{U}}-\overrightarrow{\mathrm{V}}|}+2\right)(1-C)^{-9 / 2} \text { and } C_{L}=\frac{4}{3}
\end{aligned}
$$




$$
\frac{D \varepsilon}{D t}=\nabla \cdot\left(v+\frac{v_{t}}{\sigma_{\varepsilon}}\right) \nabla \varepsilon+\frac{\varepsilon}{k}\left(C_{1 \varepsilon} P_{r}+C_{2 \varepsilon} \overrightarrow{\mathrm{g}} v_{t} \frac{\rho_{s}-\rho_{f}}{\rho_{f}} \nabla C \cdot \overrightarrow{\mathrm{k}}-C_{3 \varepsilon} \varepsilon-v_{t} F_{d} \nabla C \cdot \overrightarrow{\mathrm{k}}\right),
$$

$$
F_{d}=\frac{C}{1-C} \frac{3 C_{D}}{4 d}|\overrightarrow{\mathrm{U}}-\overrightarrow{\mathrm{V}}|^{2}
$$

$C_{1 \varepsilon}=1.44, C_{2 \varepsilon}=1.92, C_{3 \varepsilon}=1.2$,

Closure of particle stresses $[3,11]$

$$
T_{x z}=\frac{6 v \rho_{f}}{5\left[\left(C_{m} / C\right)^{\frac{1}{3}}-1\right]^{2}} \frac{\partial V_{x}}{\partial z},
$$

$$
T_{z z}=\frac{T_{x z}}{\tan \varphi}
$$

Air-water interface location [18]

$$
\frac{\partial F}{\partial t}+\overrightarrow{\mathrm{U}} \cdot \nabla F=0
$$

where $\overrightarrow{\mathrm{U}} \equiv\left(U_{x}, U_{z}\right)$ and $\overrightarrow{\mathrm{V}} \equiv\left(V_{x}, V_{z}\right)$ are the fluid and sediment velocity vectors, respectively; $\vec{U} \vec{U}$ is the velocity tensorial product; $x$ and $z$ are the coordinates in the horizontal and vertical direction, respectively; $\overrightarrow{\mathrm{T}}_{s}$ is the sediment phase stress tensor accounting for intergranular stress and Reynolds stresses of the sediment velocities; $\overrightarrow{\mathrm{T}}_{f}$ is the fluid phase stress ten- 
sor containing fluid viscous stress and fluid Reynolds stresses; $C$ is the sediment phase volume concentration; $C_{m}$ is the maximum static sediment concentration; $P$ is the pressure; $P_{r}$ is the production of turbulent energy due to shear stress; $\overrightarrow{\mathrm{g}}$ is the gravitational acceleration;

$\overrightarrow{\mathrm{k}}$ is the unit vector in the $z$ direction; $\rho_{f}$ and $\rho_{s}$ are the fluid and sediment densities, respectively; $\overrightarrow{\mathrm{f}}_{\text {in }}$ represents the hydrodynamic interphase forces containing resistance (drag) and lift forces; $d$ is the particle diameter (here the sediment grains are assumed to be equalsized, identical spheres); $C_{D}$ and $C_{L}$ are the drag and lift coefficients, respectively; $\varphi$ is the internal friction angle of sediment; $v$ is the kinematic viscosity; $v_{t}$ is the eddy viscosity; $F$ is the fluid volume per numerical cell volume; $T_{X z}$ and $T_{z z}$ are the horizontal and vertical intergranular stresses, respectively; $\nabla \equiv(\partial / \partial x, \partial / \partial z)$ is gradient operator and $\frac{D()}{D t}$ is the material derivative.

\subsection{Initial and boundary conditions}

The initial conditions for the turbulence field follow the numerical experiments of Lin and Liu [30]. At the air-water interface, the fluid turbulence has zero vertical fluxes of $k$ and $\varepsilon$. Near the bed, the boundary conditions for $k$ and $\varepsilon$ are defined according to the turbulent boundary layer theory taking account of the influence of the moving sediments on the fluid phase with the log-law velocity profile applied at the bottom [33]. At the bottom boundary, the no-slip condition applies for both the fluid and sediment velocities. The sediment concentration at this boundary was taken as the maximum concentration $\left(C_{m}=0.65\right)$. At the top boundary a zero-flux sediment concentration condition was applied: 


$$
C \overrightarrow{\mathrm{V}} \cdot \overrightarrow{\mathrm{k}}-v_{t} \nabla C \cdot \overrightarrow{\mathrm{k}}=0 .
$$

The initial sediment concentration profile for suspended sediment transport under the waves was [40]:

$$
C(x, Z, 0)=C_{m} \exp \left(\frac{-Z}{l}\right)
$$

where $I$ is the vertical length scale that is roughly equal to the ripple height for rippled beds [40] and for sheet flow conditions it is generally of the order $30 \mathrm{~d}$. The generating-absorbing boundary condition introduced by Petit et al. [44] was implemented at the entering boundaries for incident wave generation and absorbing the reflected waves [5].

\subsection{Numerical Scheme}

The governing equations, including the two-dimensional NS equations for fluid and sediment phases, VOF change function and $k$ - $\varepsilon$ equations, were discretized using finitedifference methods. A staggered grid was used for the calculation domain. Scalar variables were calculated in the center of numerical cells and the vector components were calculated from the staggered grid. The Cartesian coordinate system was used with the $x$-axis in the cross-shore direction and $z$-axis normal to the horizontal direction. The calculations started from the still water condition and the time step was determined by iteration until the computational stability $[4,5]$ was achieved.

\section{Numerical Experiments and Discussion}

The model was used for simulating the behavior of wave-driven sediment transport in the nearshore zone. A series of numerical experiments were performed for a number of 


\subsection{Simulated sediment concentration and velocity}

Wave propagation, instantaneous sediment concentration and velocity in the surf zone at different cross-shore distances are presented in Fig. 2. In the surf zone, the dominant hydrodynamic process is wave breaking. When a wave approaches the shore, its steepness increases due to the depth reduction. Flows and sediment transport characteristics vary across the surf zone. To investigate these variations, three different locations are considered: the seaward limit, middle and landward limit of surf zone are considered (as shown in Fig. 1).

From $x=5 \mathrm{~m}$ to $6.45 \mathrm{~m}$, the maximum sediment concentrations start to increase after the peak onshore flow. Near the seaward limit, the cross-shore flow velocity is generally less than $1 \mathrm{~ms}^{-1}$ (Fig. 2a), but this may be exceeded during wave propagation. It is evident that the highest cross-shore velocity occurs at $x=6.45 \mathrm{~m}$. The magnitude of the cross-shore flow velocity in this zone frequently exceeds $1 \mathrm{~ms}^{-1}$ and may reach $1.5 \mathrm{~ms}^{-1}$. Inside the surf zone, the sediment concentration is high around the times of the maximum cross-shore velocity as shown by numerical experiments. However, before and after this time, it is noticed that a change in the sediment concentration develops as the wave front approaches, subsequently becoming significant as the sediment suspension takes place. The sediment concentration increases sharply just before the maximum velocity, and decreases with the decline of the velocity. This increase/decrease of sediment concentration suggests that the sediment particles are first suspended and then fall back to the lower part of water column, leading to the concentration peaks around the maximum velocity. The plots show the periodicity of motion and effect of increasing the wave steepness. The wave steepening continues to a certain extent until finally the wave breaks. These breaking waves increase the average water velocity, turbulence and as a result the mixing rate. An increase in the mixing rate enhances sediment 
suspension. The suspended sediments are transported by the currents developed from wave breaking. Hence, it is confirmed that the wave breaking is an important feature of nearshore sediment transport and as a result impacts on coastal morphology.

Figure 3 shows the temporal variation of velocity and sediment concentration in the swash zone. The panels show the cross-shore velocity and sediment concentration at $x=7.3$, 7.6 and $7.8 \mathrm{~m}$ that represent the lower, mid and upper swash zone (as depicted in Fig. 1). It can be seen from Fig. 3 that the velocity in the swash zone reaches its maximum at the start of the uprush and at the end of the backwash. Figure 3 indicates that, in contrast to the surf zone, the relative time ( $t / T$ where $T$ is the wave period) does not reach unity, meaning that the beach is immersed less than $100 \%$ of the wave period. Meanwhile, the duration of the swash event (when beach is immersed) reduces towards the shore. These results are consistent with findings about sediment transport in the swash zone from previous experiments [35]. Figure 3a illustrates that the sediment transport in the lower region of the swash zone is relatively small and largely towards the offshore. The distribution of velocity is asymmetrical, with a higher magnitude during the backwash. This is accompanied by higher sediment concentrations. The flow direction changes at $t / T=0.3$, thus the duration of the backwash is longer than that of the uprush. The maximum sediment concentration (often exceeds $0.3)$ occurs at the start of swash cycle $(t / T=0)$ and may reach zero during flow reversal. Another peak in the sediment concentration takes place at the end of the swash cycle. While the duration of the uprush and the sediment concentration in the uprush are less than the duration and sediment concentration in the backwash in the middle part of the swash zone, the coastal sediment velocity distribution is more symmetrical (Fig. 3b). Figure 3c shows that the highest value of sediment concentration takes place at the beginning of the uprush, 
approaches zero in the middle of the swash event, and then increases again at the end of backwash. Comparison of Fig. 3b and c shows that the velocity and sediment concentration during the uprush in the upper part of swash zone are higher than the corresponding values in the middle region of the swash zone. In contrast, the amount of sediment concentration and velocity at the end of backwash in the middle part of swash zone are higher than the corresponding values in the upper region of swash zone. This result is consistent with current understanding of the time distribution of sediment concentration in the swash zone [1]. Generally, there is an asymmetric distribution in the sediment concentration in the swash zone. Aagaard and Hughes [1] proposed, based on their field measurements, that the vertical velocity fluctuations generated by eddies can be important for the process of sediment suspension and can contribute to asymmetrically distributed sediment transport rates between the uprush and backwash phases of the swash cycle.

In order to examine further the behavior of the wave-induced sediment activity, the profile change in sediment concentration was computed. The vertical variation of average sediment concentration during the wave period at different cross-shore distance is presented in Fig. 4. As can be seen from this figure, sediment concentrations near the bed are considerably more severe than the concentration near the free surface. The maximum vertical gradient of suspended sediment is close to the free surface, under the wave crest. Near the breaking point (e.g., $x=6.45 \mathrm{~m}$ ), sediment concentration in the upper part of water and vertical variations of suspended sediments are higher in comparison to a beginning of surf zone $(x=5$, $5.5 \mathrm{~m}$ ). Bakhtyar et al. [4] studied the surf-swash motions and observed that "After breaking, momentum from the crest region of the wave convects below the trough level. In this region, the incoming wave motion interacts with offshore directed drainage (from previous waves)". 
The variation of sediment concentration is generated by this mixing of on- and offshore wa-

ter movement, which involves the exchange of turbulence and momentum [4]. Moreover, the concentration profiles in Fig. 4 confirm that after the breaking point and especially in the swash zone $(x=7.3 \mathrm{~m})$, the dominant mode of sediment transport is sheet flow; nevertheless suspended sediments also exist.

\subsection{Simulated sediment flux and beach profile}

Sediment fluxes were computed by multiplication of the sediment velocities and the sediment concentrations. Instantaneous sediment fluxes in the surf zone at $x=5,6$ and $6.45 \mathrm{~m}$ are shown in Fig. 5. The results show that the cross-shore sediment transport in this zone typically increases towards the shore. The correspondence between the sediment flux variation and the velocity field (e.g., Figs. 2 and 5) is apparent. However, for the areas with zero sediment concentration, the sediment fluxes remain constant during the cycle. Figure 5 demonstrates that during the onshore acceleration, the sediment flux increases, while throughout the deceleration period, the sediment flux decreases. This may be due to the fact that the sediment is picked up and entrained into the water during the flow acceleration (sediment concentration and velocity increase, e.g., Fig. 2), while it settles out during flow deceleration (sediment concentration decrease). Figure $5 c$ shows that during the off-shoreward flow, the sediment flux has a negative sign, i.e., it is directed seaward. The sediment flux variation is more significant at on/offshore flow reversal phase than at the off/onshore flow reversal phase. This behavior is likely due to the asymmetric nature of the flow field [32].

Sediment transport in the surf and swash zones is strongly affected via momentum transfer due to the fluid-sediment and particle-particle interactions. The observed characte- 
ristics of sediment transport are attributed to the vertical momentum transfer between the fluid and sediment phases [49]. In the bed-load regime near the bed, the vertical motion of moving sediments is negligible since the high concentration of moving sediments induces a common interparticle contact. Therefore, the particle momentum in this layer is preserved and the velocity gradient is rather large. In contrast, in the suspended layer where the concentration is low and sediment entrainment is insignificant, the vertical motion of sediments between the upper and lower layers is active due to momentum exchange; therefore, the velocity gradient is kept small. The interphase momentum transfer in the suspended layer is enhanced as the interparticle collision becomes less frequent than that in the bed-load layer.

The temporal variations of sediment flux at different cross-shore distances in the swash zone are shown in Fig. 6. Panel (a) shows that in the lower swash zone $(x=7.3 \mathrm{~m})$, the duration of backwash is greater than that of the uprush, with runup moving sediment onshore while the rundown motion induces strong offshore sediment transport. Consequently, the backwash induces a larger transport rate than the uprush, indicating that the backwash is more important than the uprush for sediment transport. However, the backwash sediment transport decreases and the uprush sediment transport increases towards the shore as shown in panels (b) and (c). It is evident that the uprush induces a larger sediment flux than the backwash, indicating that the uprush is more important than the backwash for sediment transport at $x=7.8 \mathrm{~m}$ (upper swash zone). While intensive on-shore and off-shore sediment transport occur during uprush and backwash respectively, the difference of their rates is typically small, resulting in relatively little net sediment transport and beach profile change in the swash region over the wave cycle. Generally, a net on-shore transport of sediment oc- 
curs in the swash zone because the uprush is more important for sediment transport than the backwash.

After calculating the sediment volume concentration in each cell, the beach profile can be simulated. Figure 7 displays the predicted beach profile in the surf and swash zones. These results provide insight into the foreshore beach evolution. The predicted profile exhi-

bits erosion below the still water level and formation of berm above the still water level. The greatest erosion takes place near the wave-breaking point. In addition, wave motion and as a result the sediment transport induced the generation of bar beneath the still water level.

\subsection{Effect of beach and wave characteristics on sediment flux}

Sediment transport in the nearshore region is dependent on the wave energy. This energy $\left(E_{W}\right)$, transmitted in the direction of wave propagation, is given in terms of the wave conditions and is proportional to the square of wave height [51]:

$$
E_{w}=f\left(H^{2}\right),
$$

According to this equation, an increase in the wave energy and hence sediment flux can be induced by increasing wave height. In order to better understand the distribution and transport of sediments in the surf and swash zones, the spatial distribution of sediment transport is given in Fig. 8. Figure 8 depicts the spatial variation of sediment flux with different wave heights over a wave cycle. It can be observed that the peak of the sediment flux shifts upward with increasing wave height. In the surf zone, the transport flux increases towards the beach until the wave breaks whereas in the swash zone it decreases towards the maximum wave runup. 
diment transport [10]. In order to examine further the behavior of the sediment distribution, its relative change with the sediment grain size was calculated. Figure 9 presents the resulting sediment flux for different sediment diameters. Generally, sediment transport is inversely related to grain size; thus, transport flux of smaller particles is higher than that of larger particles. For fine sediments, the suspension mode of transport is likely to dominate whereas for coarse sands, bed-load is the prevailing transport mode. Figure 9 also shows two peaks in the spatial distribution of sediment flux in the nearshore zone. In the surf zone, the sediment flux increases towards the shore until the wave breaks. Nevertheless, in the swash zone, the amount of sediment flux decreases towards the shore. The wave energy is dissipated significantly due to turbulence after the wave breaking. Despite this energy dissipation, wave breaking enhances momentum exchange between the sediment and fluid phases, interaction between the grains (intergranular stresses) and hence sediment transport in form of sheet flow. Furthermore, pre-suspended sediments due to wave breaking are transported into the swash zone by the flow, intensifying sediment transport in this area.

Velocity time series for different wave periods at different locations in the surf zone are shown in Fig. 10. The sediment velocity for the shorter period is higher than that of longer period, as is evident in Fig. 10.This is likely due to the fact that wave motion with the shorter wave period induces higher wave energy flux and consequently higher velocity than the longer period. 


\subsection{Simulated turbulence field}

An important issue concerning wave motions in the surf and swash zones is the distribution of turbulent kinetic energy (TKE). It is often conjectured that sediment transport is tied in a direct way to dynamics of turbulence in the surf zone [47]. Turbulence has been found to play an important part during both the uprush and the backwash [4]. Moreover, turbulent flows have been found to contribute significantly to the transport of momentum and mass in wave motions and have a determining influence on the distributions of sediment transport in the swash zone [34]. Therefore, the rate and the direction of sediment transport, turbulence dynamics and their spatial and temporal variations should be well understood.

At low sediment concentrations, local fluid turbulence remains nearly unchanged as compared with clear water. In other words, the motions of sediments may be computed assuming that they do not have any major effect on the fluid turbulence, and the turbulence may be represented by any reasonable single-phase flow model [13]. However, in dense sediment-fluid mixtures, like those that are usually found in surf and swash zones, the presence of the sediments changes the fluid-phase turbulence significantly. Sediment transport may lead to further turbulence dissipation. The sediments that cannot react to the turbulent velocity fluctuations exert a force on the fluid that opposes the relative motion. When the sediment concentrations are high, the relative motion is generally produced by the fluid phase fluctuations. The cloud of sediments produces a non-uniform force field that instantaneously opposes the fluid phase velocity fluctuations, thus extracting energy from the turbulence. Therefore, energy is taken from the fluid turbulence and transferred to the transported sediments [13]. 
during the wave breaking process is found to be about $0.02 \mathrm{~m}^{2} \mathrm{~s}^{-2}$. Furthermore, the highest

TKE is near the breaking point, where it is one order of magnitude greater than that in seaward limit of surf zone.

\subsection{Simulated different breakers and different beach types (dissipative and intermediate)}

Breaking types and wave characteristics at the breaking point can be predicted by use of non-dimensional parameters. Generally the surf similarity parameter [27] has been used to characterize a breaker type and surf zone hydrodynamics as follows:

$$
\zeta_{0}=\frac{\tan \beta}{\sqrt{\left(H_{0} / L_{0}\right)}}
$$

where $\beta$ is the bed slope; and $H_{0}$ and $L_{0}$ are the height and length of incident waves in deep water, respectively. When $\zeta_{0}<0.5$, spilling breakers occur, changing to plunging breakers for $0.5<\zeta_{0}<2$ [16]. The aforementioned breaker types were used for the investigation of surf zone hydrodynamics. In order to evaluate the effect of wave-breaking type on sediment transport in more detail, the spatial variation of sediment transport in the nearshore for both spilling and plunging breakers are examined in Fig. 12. Numerical experiments were carried out for two different wave conditions: a spilling breaker of period $2.4 \mathrm{~s}$ and a plunging breaker of period 3.4 s. As shown in Fig. 12, the distributions of sediment flux show a clear difference between the two different breaker types. In the nearshore zone, the sediment flux under the plunging breaker is higher in comparison to that under a spilling breaker. The 
maximum sediment flux occurred in the vicinity of the breaker line from 6.5 to $7.5 \mathrm{~m}$, the source of which was attributed to the bed erosion in the surf zone.

Wave, water elevation and flow characteristics in the swash zone are an essential basis for the evaluation of the shoreline and coastal profile changes. Accurate simulation of sediment transport in this zone depends on how well the hydrodynamics are described in the numerical model. A parameter employed to determine the hydrodynamics and morphodynamics of swash zone is the surf scaling parameter, $\xi$, defined as [17]:

$$
\xi=\frac{H_{b} \omega^{2}}{2|\overrightarrow{\mathrm{g}}| \tan ^{2} \beta},
$$

where $\omega$ is the angular frequency and the subscript $b$ denotes the breaking point. Dissipative conditions exist for $\xi>20$ and intermediate conditions for $2.5<\xi<20$. Dissipative beaches are typically flat and associated with fine sands, high wave energy and wide surf zones. Intermediate beaches are usually steep and associated with coarse sands, low wave energy and narrow surf zones [38]. In this section, the results of numerical experiments for the aforementioned beach types and different conditions of swash zone hydrodynamics are presented and compared. Numerical experiments were carried out for two different beach conditions: a dissipative beach with a wave of period $2.4 \mathrm{~s}$ and an intermediate beach with a wave of period 3.4 s. Figure 13 shows the comparison between temporal velocities for dissipative and intermediate beaches at different cross-shore locations. As shown in Figs. 13a and $b$, the flow in the surf zone at the intermediate beach is more intense (with a larger flow velocity magnitude) than that at the dissipative beach. Figure 13c shows the velocity distribution in the swash zone. The magnitude of flow velocity at the dissipative beach during 
both the uprush and backwash is smaller than that at the intermediate beach. These results are consistent with the field results of Miles et al. [38]. Miles et al. [38] investigated the sediment transport process in the swash zone for different conditions and indicated that the velocity variance, and mean suspended sediment concentrations were greater on intermediate beaches than on dissipative beaches.

\section{Summary and conclusions}

A two-phase flow model has been developed to analyze numerically surf and swash zones sediment transport under the influence of wave breaking and wave runup. This model was formulated for the two key physical processes involved: wave motion on the beach and nearshore sediment transport. Interactions among the processes are incorporated in the model. The present two-fluid Eulerian-Eulerian model is based on the mass and momentum conservation equations for both sediment and fluid phases, the VOF technique for tracking the free surface motion and a $k-\varepsilon$ turbulence closure model for describing the generation and dissipation processes of turbulence. In summary, the simulation results agree qualitatively with previous experimental observations of sediment transport in the surf and swash zones and demonstrate that the model is capable of simulating the effects of wave motions on sediment transport and beach profile changes. According to the analysis of this study, the following conclusions are drawn:

- Most mathematical models available for simulating sediment transport in oscillatory flows are based on single-phase flow models. These models have limited ability in simulating the fluid-sediment interactions and are not suitable for predicting the velocity and 
2

3

concentration changes with time. A two-phase flow model provides a powerful simulation tool for studying the sediment transport and hydrodynamics in the surf and swash zones.

- The wave breaking and runup are well described by the flow model, and the turbulence characteristics can be simulated well using the $k$ - $\varepsilon$ closure model. In addition, the interaction between the fluid flow and the sediment is reproduced successfully.

- Generally, there is an asymmetric distribution in the sediment concentration in the swash zone during uprush and backwash.

- The maximum sediment concentration occurs at the start of swash cycle and approaches zero during flow reversal. Subsequently the sediment concentration increases and reaches another peak at the end of swash cycle.

- In a general two-phase flow approach, especially when sediment concentration is large, the effect of sediments on carrier fluid flow and turbulence must be considered. The numerical results show that the maximum TKE is found near the breaking point.

- Larger wave heights result in higher sediment transport fluxes.

- The sediment transport is inversely related to the sediment grain size; thus, the transport flux of smaller particles tends to be greater than that of larger particles.

- Velocity and sediment concentrations were found to be greater on the intermediate beach than on the dissipative beach. 
- In the lower part of the swash zone, the backwash is more important than the uprush for sediment transport, whereas in the upper part, uprush is more important than the backwash for sediment transport.

- In the nearshore zone, the sediment flux under a plunging breaker is higher in comparison to that under a spilling breaker.

- Near the breaking point, sediment concentration in the upper part of flow column and vertical variations of suspended sediments are higher in comparison to other parts of the nearshore zone.

- The location of the maximum cross-shore sediment transport is in the vicinity of the breaking point.

This work has led to a better understanding of several important issues related to assessment of numerical models for simulating sediment in the nearshore zone. As a numerical model, the two-phase flow model requires greater computation run time and vastly increased memory relative to a classical single-phase flow model, which still restricts its use in real applications. This work suggests some directions for future research. The interactions of the nearshore zone and beach groundwater play an important role in the transfer of mass across the beach face and overall beach morphology. There is a need for numerical models to investigate the coastal aquifer and its interaction with wave motion, sediment transport and beach profile changes. 
[33] Longo S. Two-phase flow modeling of sediment motion in sheet-flows above plane beds. J Hydraul Eng 2005;131:366-79.

[34] Longo S, Petti M, Losada I. Turbulence in the swash and surf zones: A review. Coast Eng 2002; 45: 129-47.

[35] Masselink G, Evans D, Hughes MG, Russell P. Suspended sediment transport in the swash zone of a dissipative beach. Mar Geol 2005;216:169-89.

[36] Masselink G, Li L. The role of swash infiltration in determining the beachface gradient: A numerical study. Mar Geol 2001;176:139-56.

[37] Maude AD, Withmore RL. A generalised theory of sedimentation. Br J Appl Phys 1958;7:58-71.

[38] Miles J, Butt T, Russell P. Swash zone sediment dynamics: A comparison of a dissipative and an intermediate beach. Mar Geol 2006;231:181-200.

[39] Nadaoka K, Yagi H. Single-phase fluid modeling of sheet-flow toward the development of numerical mobile bed. In: Proceedings of 22nd International Conference on Coastal Engineering, ASCE; 1990. p. 2346-59.

[40] Nielsen P. Suspended sediment transport concentration under waves. Coast Eng 1986;10:23-31.

[41] Ono M, Deguchi I, Sawaragi T. Numerical modeling of sediment transport for various mode. In: Proceedings of $25^{\text {th }}$ International Conference on Coastal Engineering, ASCE; 1996. p. 3888-900.

[42] Pedrozo-Acuña A, Simmonds DJ, Otta AK, Chadwick AJ. On the cross-shore profile change of gravel beaches. Coast Eng 2006;53:335-47.

[43] Pedrozo-Acuña A, Simmonds DJ, Chadwick AJ, Silva R. A numerical-empirical approach for evaluating morphodynamic processes on gravel and mixed sand-gravel beaches. Mar Geol 2007;241:1-18.

[44] Petit HAH, Tonjes P, van Gent MRA, van den Bosch P. Numerical simulation and validation of plunging breakers using a 2D Navier-Stokes model. In: Proceedings of $24^{\text {th }}$ Conference on Coastal Engineering, ASCE; 1995. p. 511-24. 
7

8 965 10

\section{Table 1}

Summary of previous mathematical models and modeling studies of sediment transport in the surf and swash zones.

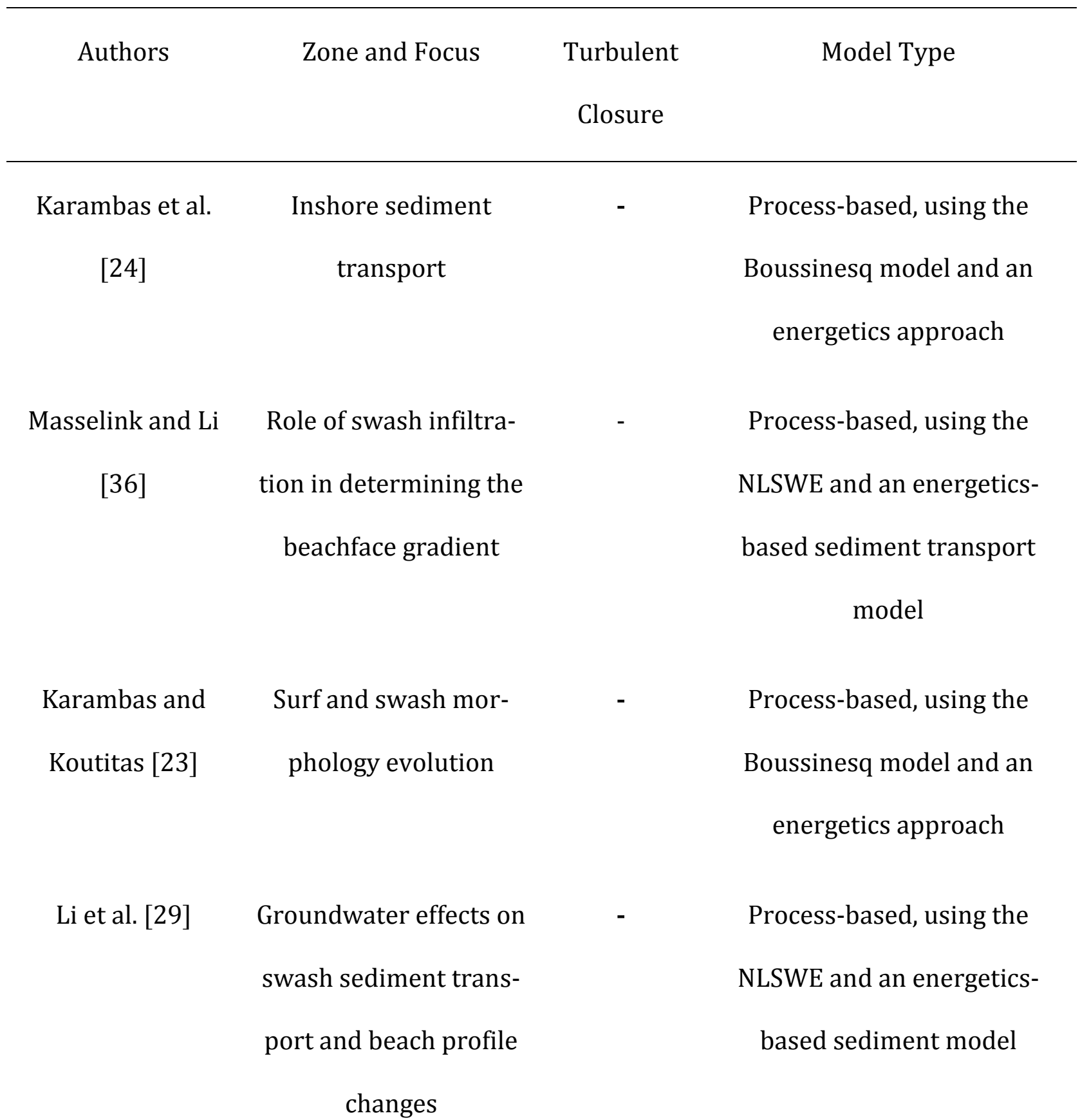




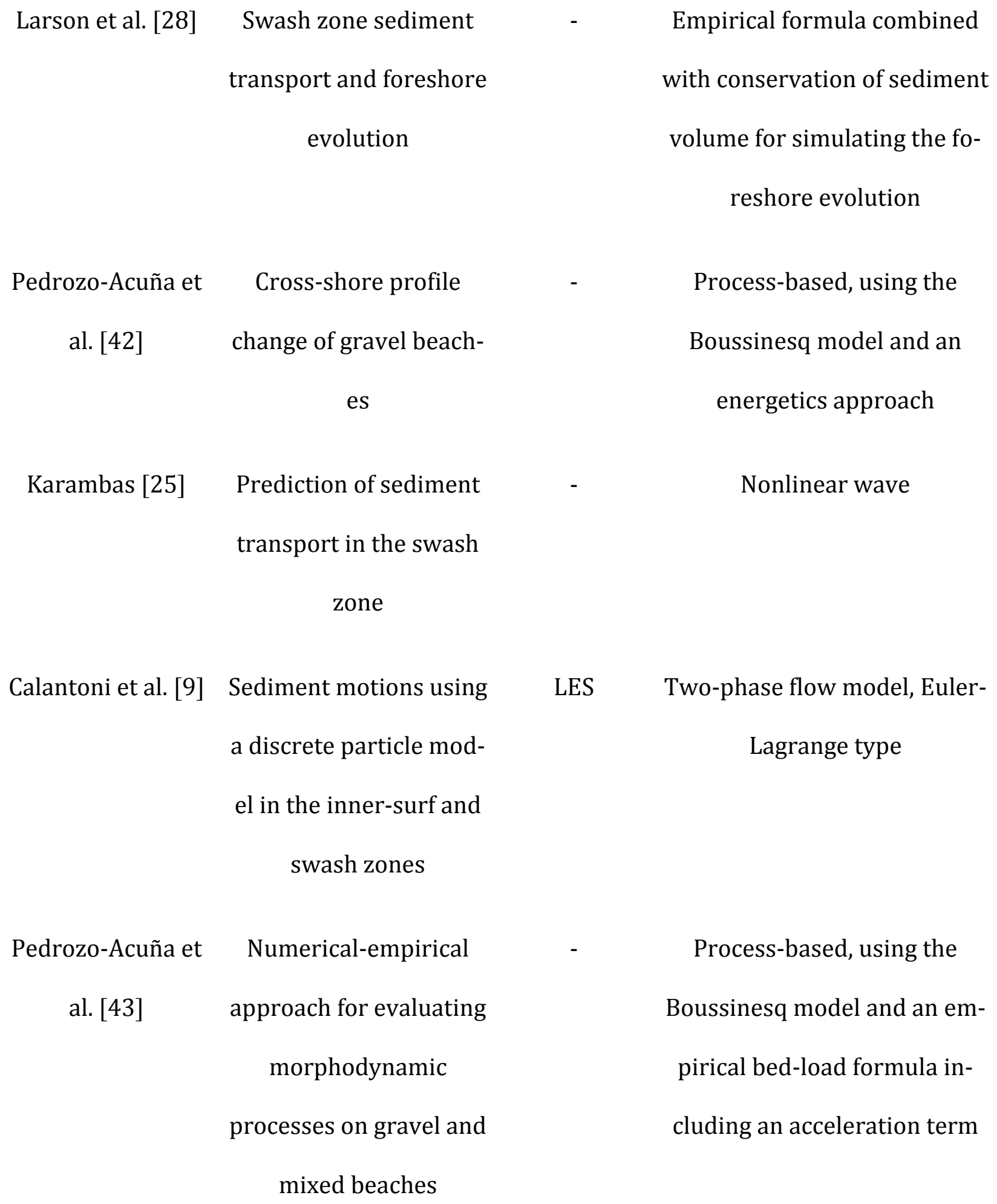


Hoque and Asano Numerical study on - $\quad$ - $\quad$ Process-based, using the

[19] wave-induced filtration

flow and its effects on

swash zone sediment

transport

Suzuki et al. [45]

Sediment concentration

under breaking waves

in the surf zone

Bakhtyar et al. [8]

$k-\varepsilon \quad$ Process-based, using the RANS

model, turbulence closure,

logical evolution in the

VOF and an energetics ap-

surf and swash zones

proach 


\section{Figure Captions}

Fig. 1. Numerical model arrangement. The numerical wave channel has a horizontal section of $3.5 \mathrm{~m}$ prior to the commencement of the slope and the beach terminates at about $5 \mathrm{~m}$ from the right hand side boundary. The three deployment locations in the swash zone are indicated by dashed vertical arrows and three selected locations in the surf zone are indicated by dashed horizontal arrows.

Fig. 2. Instantaneous velocity and sediment concentration in the surf zone at $x=$ (a) 5; (b) 6; and (c) $6.45 \mathrm{~m}$. Six concepts found in coastal engineering are shown, including two onshore durations (acceleration and deceleration), two offshore durations (acceleration and deceleration), and on/offshore flow reversal and off/onshore flow reversal times.

Fig. 3. Instantaneous velocity and sediment concentration in the swash zone at $x=$ (a) 7.3; (b) 7.6; and (c) $7.8 \mathrm{~m}$. The beach is immersed for less than $100 \%$ of the wave period in this zone. The start and end of the swash cycle, duration of uprush and backwash, and time of flow reversal are also shown in figure.

Fig. 4. Mean concentration profiles at different cross-shore distances (listed in the figure), where $h$ is the flow depth and $\eta$ is the elevation above the bed.

Fig. 5. Instantaneous sediment flux in the surf zone at $x=$ (a) 5; (b) 6; and (c) $6.45 \mathrm{~m}$. For each plot, positive and negative values indicate the onshore transport flux direction (flowing away from the wave-generator) and offshore (flowing towards the wavegenerator), respectively (as shown in c). 
Fig. 9. Spatial distributions of sediment flux in cross-shore direction for different sand grain sizes (listed in the figure).

Fig. 10. Time series of velocity for different wave periods at different locations (listed in the figure), $x=$ (a) 5 and (b) $5.6 \mathrm{~m}$.

Fig. 11. Spatial distributions of turbulent kinetic energy (TKE) in the cross-shore direction.

Fig. 12. Spatial distributions of sediment flux in the cross-shore direction under spilling and plunging breakers.

Fig. 13. Temporal variation of velocity for different wave heights in the surf zone: $x=$ (a) 5 and (b) $5.6 \mathrm{~m}$; and swash zone: (c) $x=7.6 \mathrm{~m}$. 
Fig. 1. Numerical model arrangement. The numerical wave channel has a horizontal section of $3.5 \mathrm{~m}$ prior to the commencement of the slope and the beach terminates at about $5 \mathrm{~m}$ from the right hand side boundary. The three deployment locations in the swash zone are indicated by dashed vertical arrows and three selected locations in the surf zone are indicated by dashed horizontal arrows. 


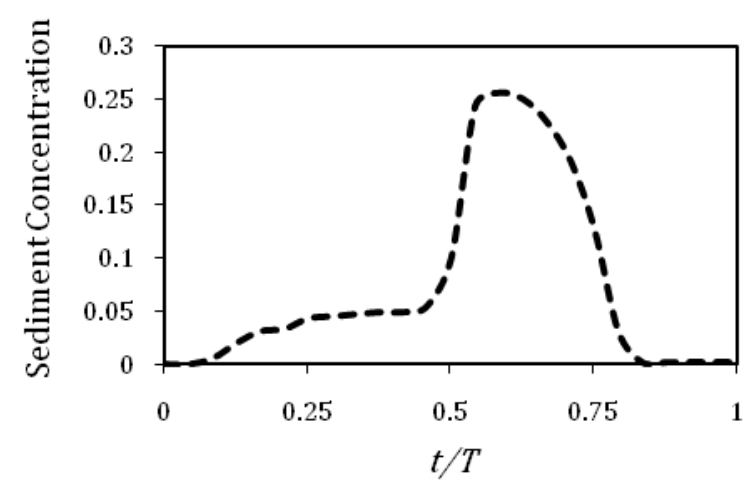

(a)

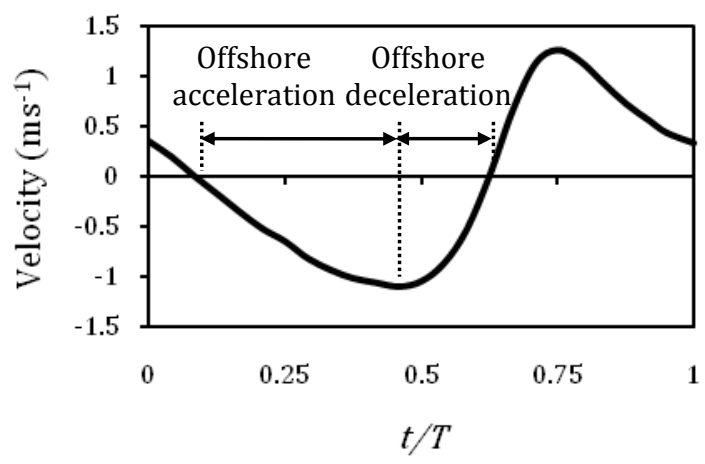

(b)
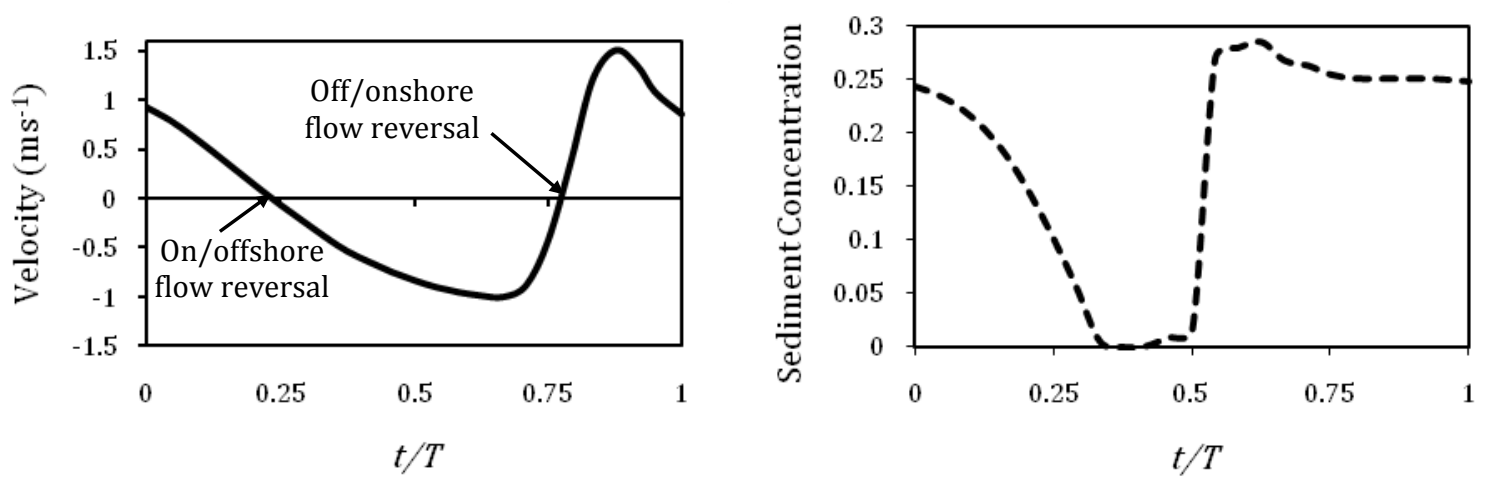

(c)

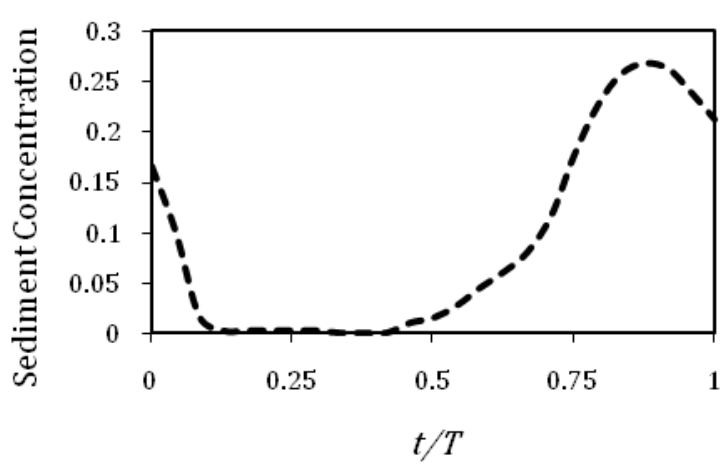

Fig. 2. Instantaneous velocity and sediment concentration in the surf zone at $x=$ (a) 5; (b) 6; and (c) $6.45 \mathrm{~m}$. Six concepts found in coastal engineering are shown in this figure, which include two onshore durations (acceleration and deceleration), two offshore durations (acceleration and deceleration), on/offshore flow reversal phase and off/onshore flow reversal phases. 

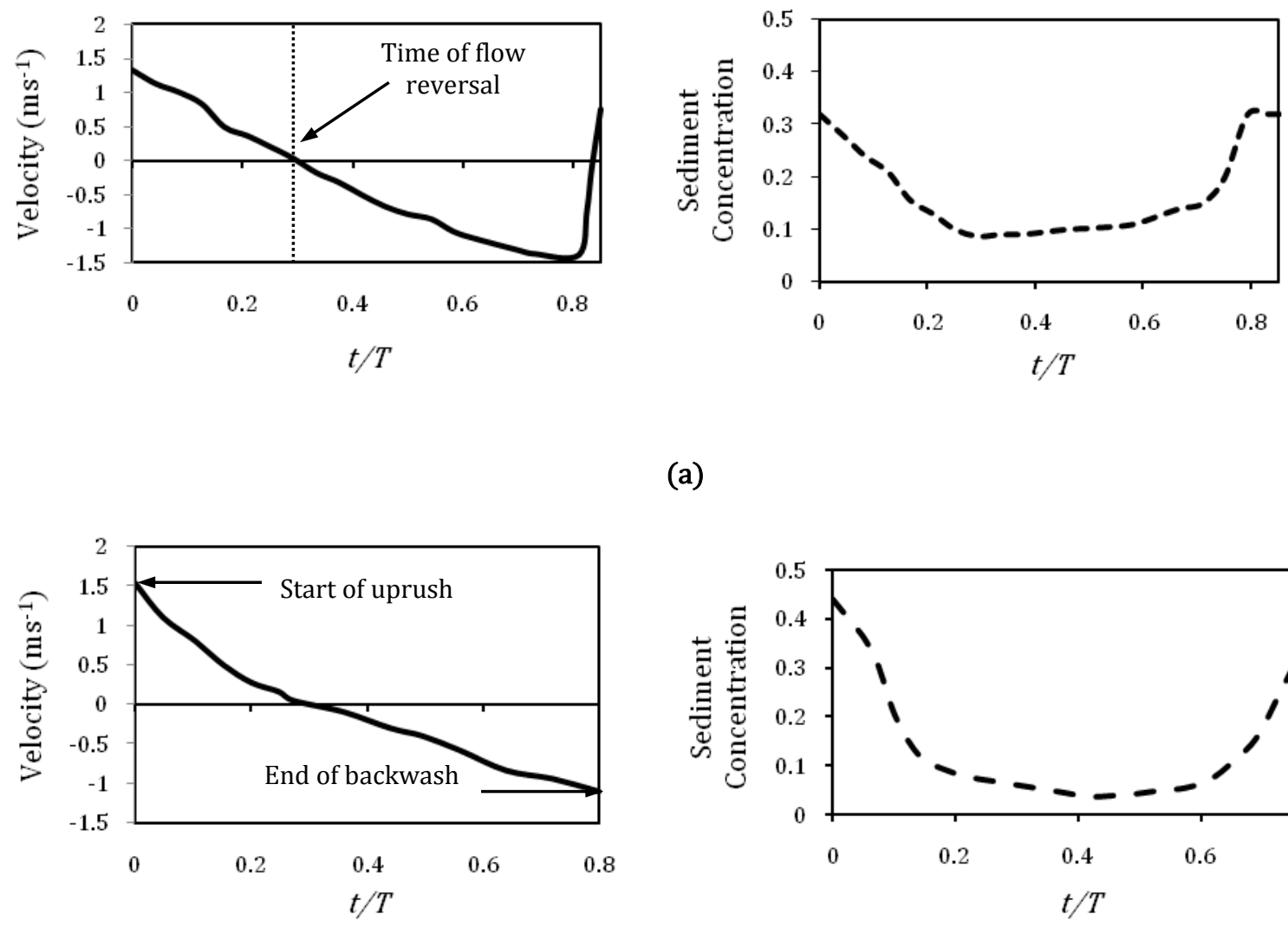

(a)

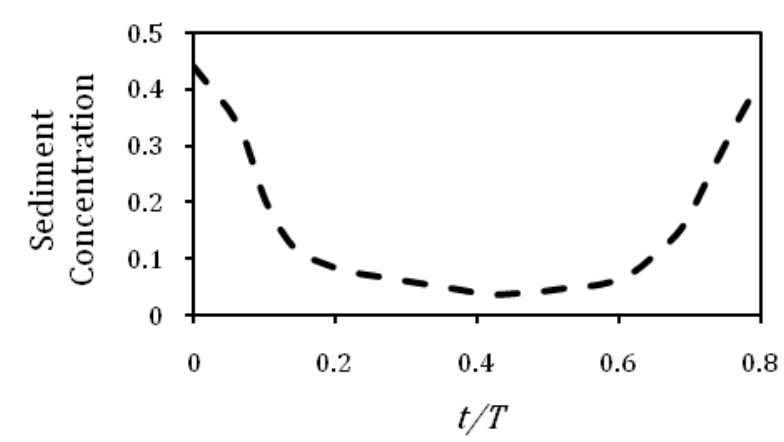

(b)
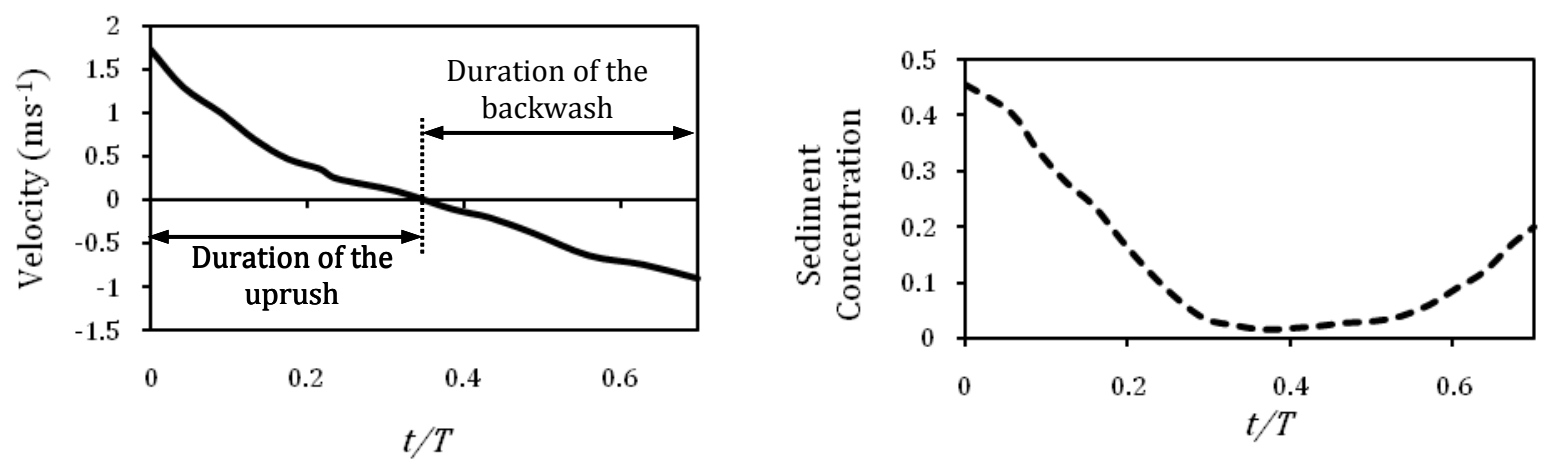

(c)

Fig. 3. Instantaneous velocity and sediment concentration in the swash zone at $x=$ (a) 7.3; (b) 7.6; and (c) 7.8 $\mathrm{m}$. The relative time $(t / T)$ does not reach unity because the beach is immersed for less than $100 \%$ of the wave period in this zone. The start and end of the swash cycle, duration of uprush and backwash, and time of flow reversal are also shown in figure. 


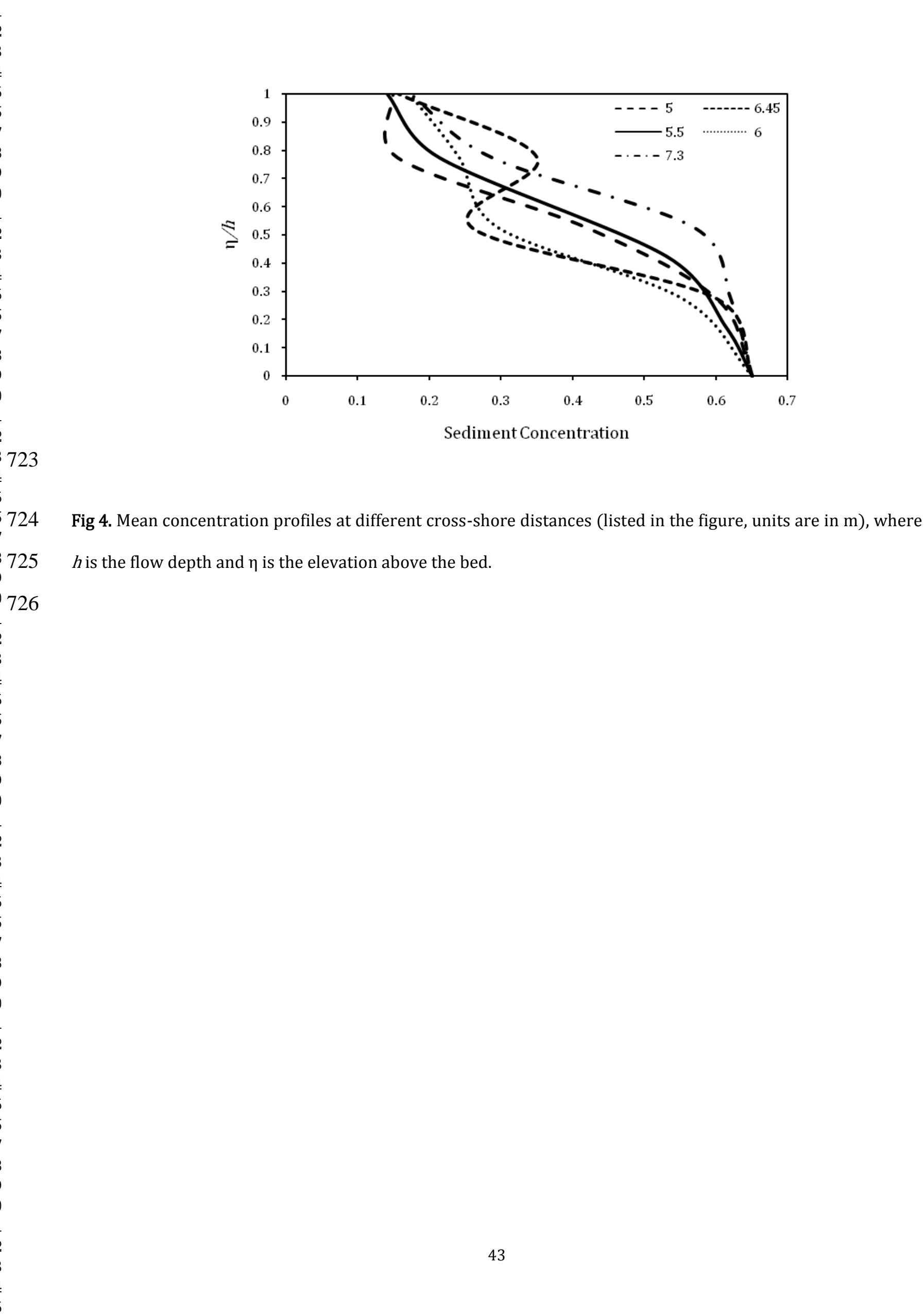




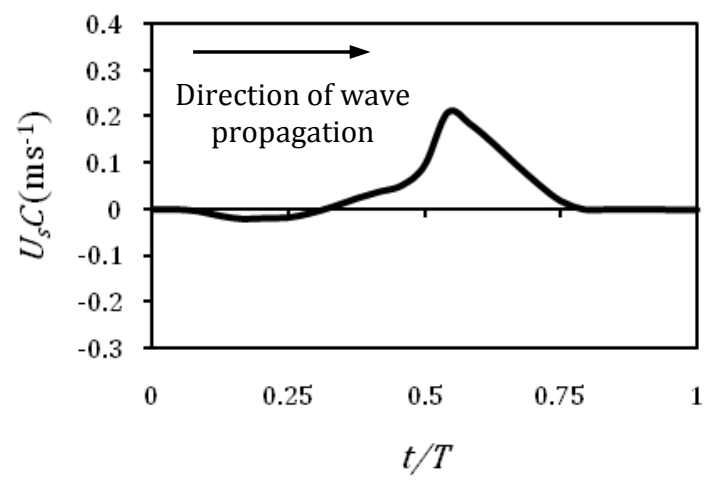

(a)

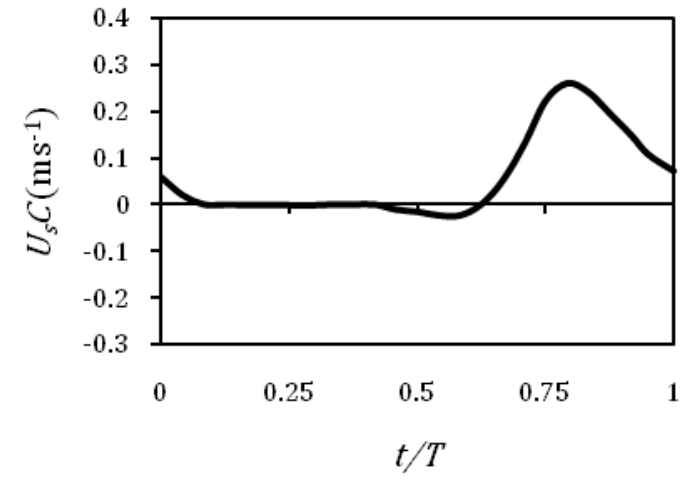

(b)

Fig. 5. Instantaneous sediment flux in the surf zone at $x=$ (a) 5; (b) 6; and (c) $6.45 \mathrm{~m}$. For each plot, positive and negative values indicate the onshore transport flux direction (flowing away from the wave-generator) and offshore (flowing towards the wave-generator), respectively (as shown in c). 


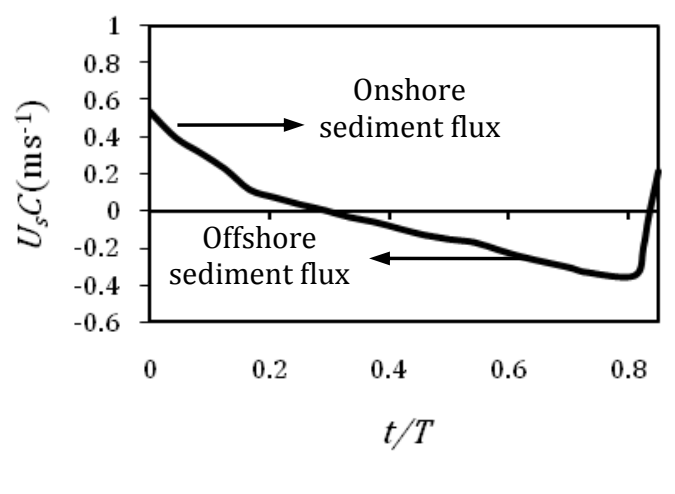

(a)

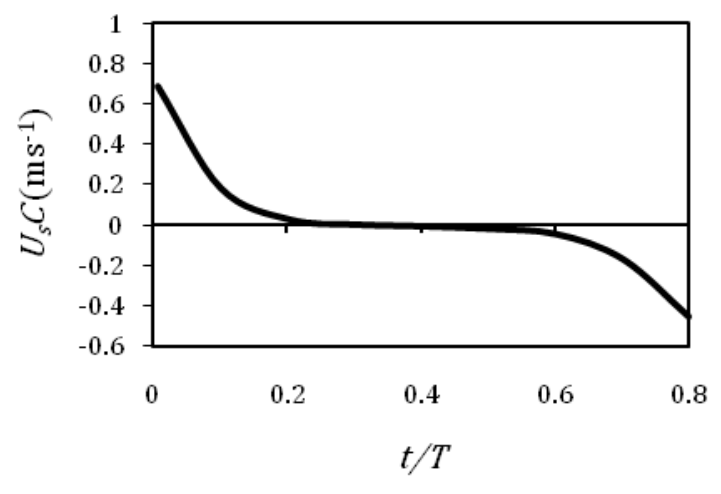

(b)

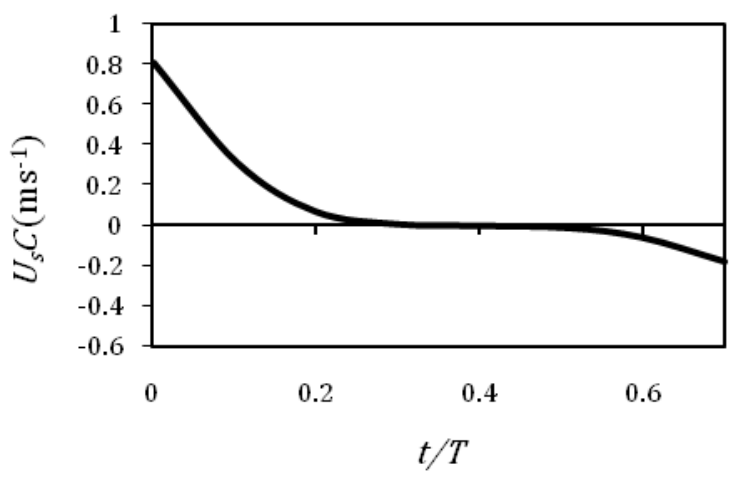

(c)

Fig. 6. Instantaneous sediment flux in the swash zone at $x=$ (a) 7.3; (b) 7.6; and (c) 7.8 m. For each plot, positive and negative magnitudes signify onshore and offshore transport flux directions, respectively. 

28

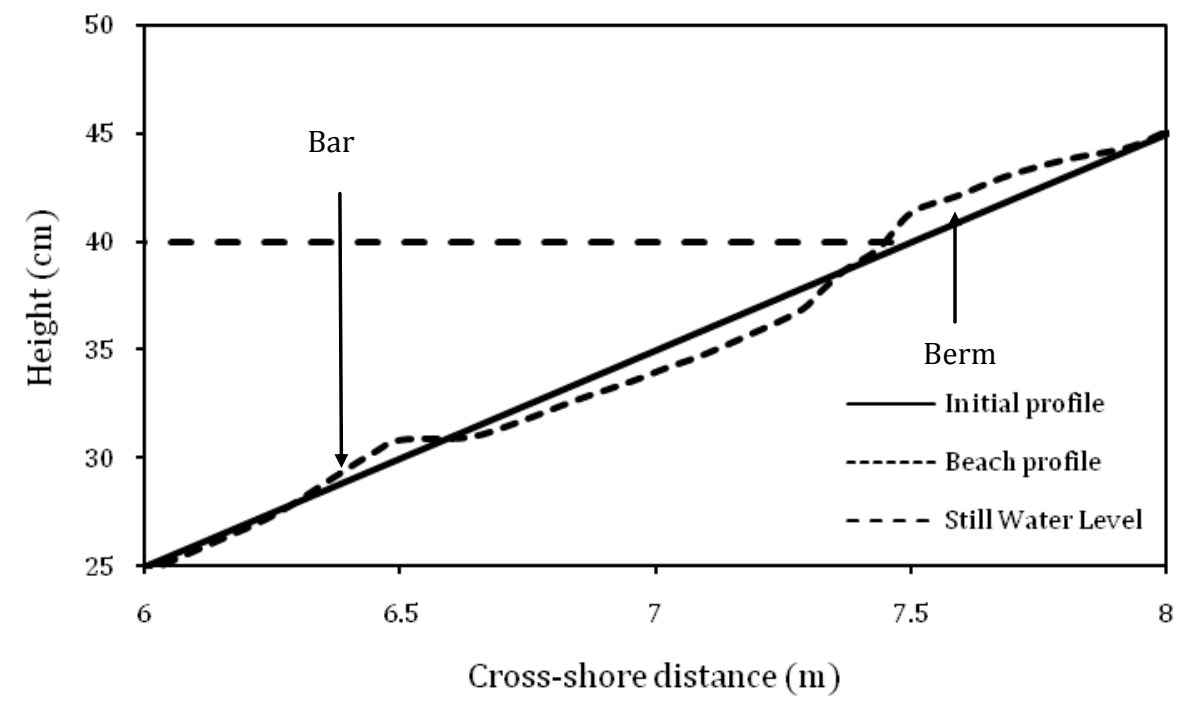

Fig. 7. Predicted beach profile in the surf and swash zones. The plot shows generation of a bar and erosion below the still water level and deposition above the still water level. 
Fig. 8. Spatial distributions of sediment flux in the surf and swash zones for different wave heights (listed in the

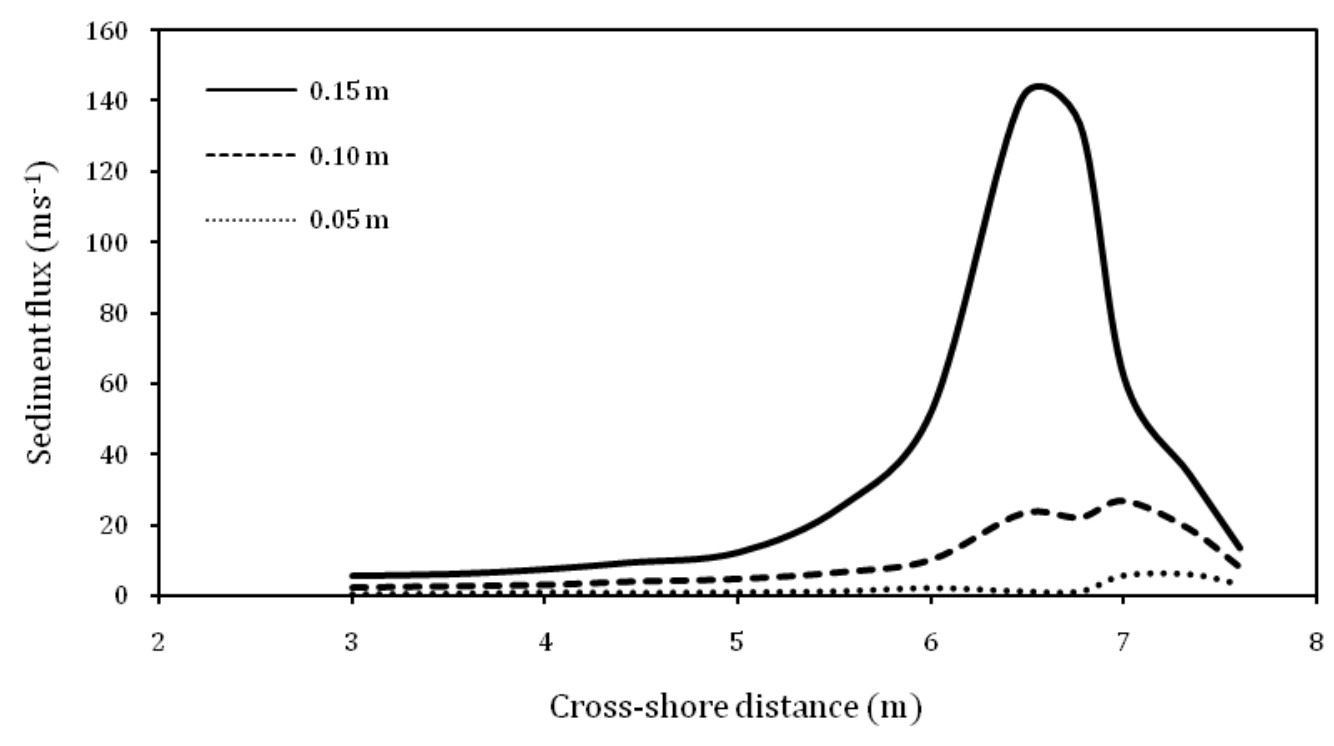

figure). 
2

5

6

7

8

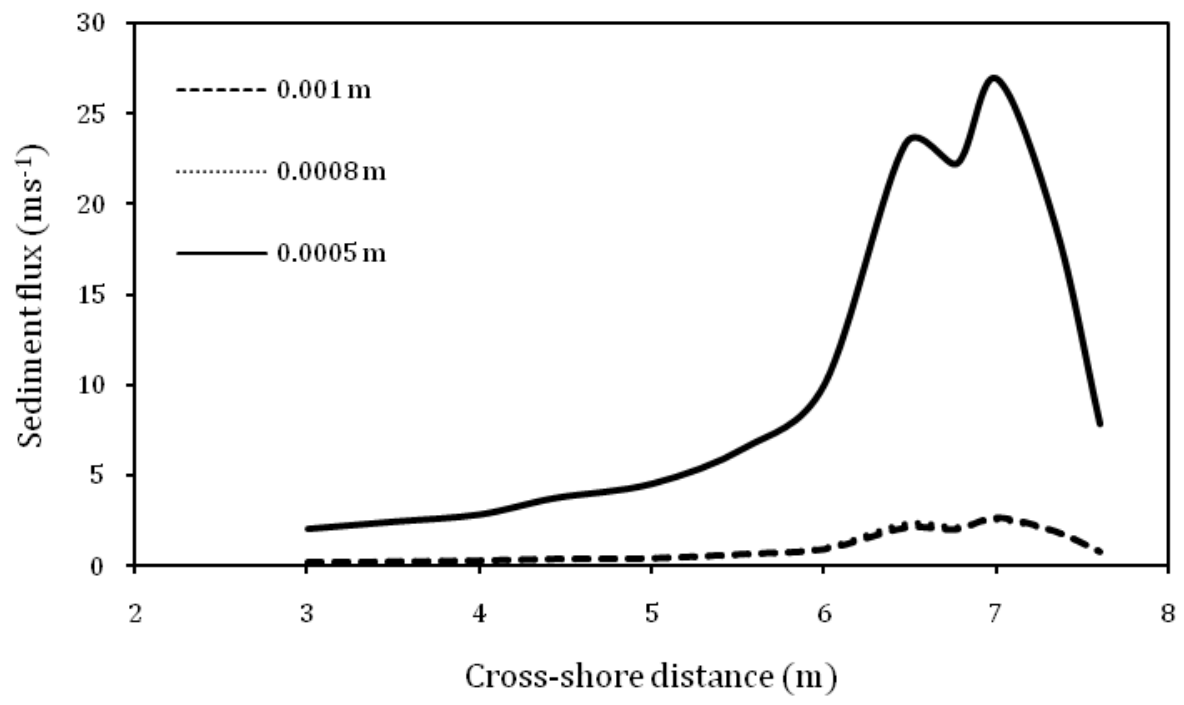

Fig. 9. Spatial distributions of sediment flux in cross-shore direction for different sand grain sizes (listed in the figure). The dashed-line is under dotted-line. 
1

2

3

5

6

7

8

9

10

11

12

13

14

15

16

17

18

19

20

21

22

23758

24

25

28

29

30

31

32

33

34

35

36

37

38

39

40

41

42

43

44
45 760

46761

47

48

49
50 762

51
52 763

$$
53
$$

54764

55

56

57

58

59

60

61

62

63

64

65

(5)

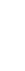

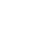

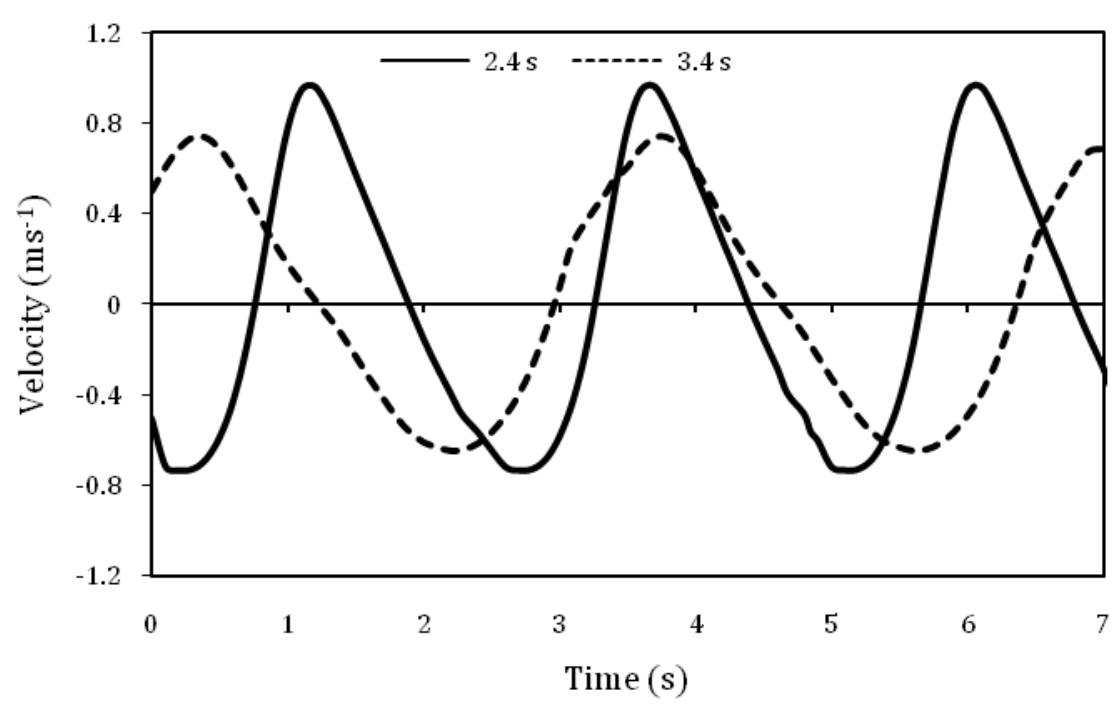

(a)

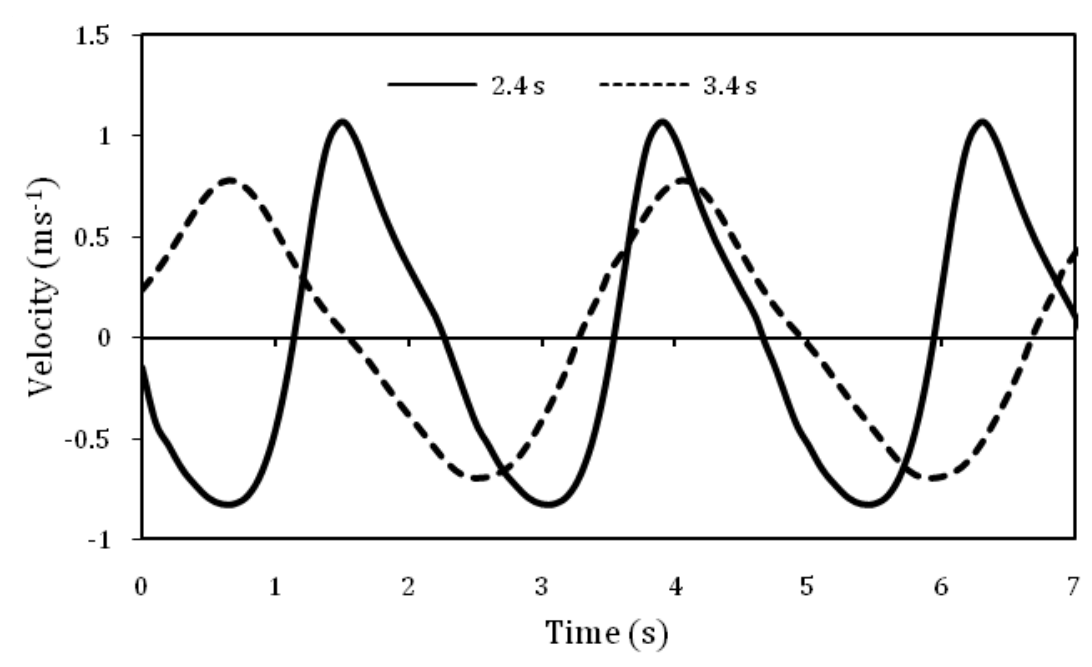

(b)

Fig. 10. Time series of velocity for different wave periods at different locations (listed in the figure), $x=$ (a) 5 and (b) $5.6 \mathrm{~m}$. 
2

3

4765

5

6

7

8

9

10

11

12

13

14

15

16

17

18

19

20

21766

22

23

24767

25

26768

27

28

29

30

31

32

33

34

35

36

37

38

39

40

41

42

43

44

45

46

47

48

49

50

51

52

53

54

55

56

57

58

59

60

61

62

63

64

65

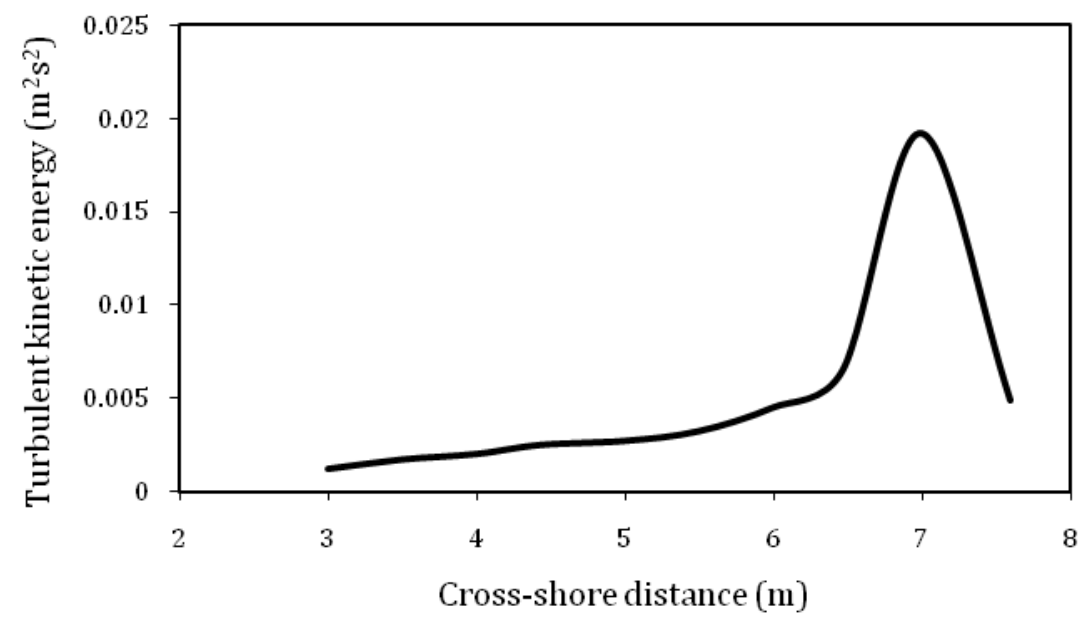

Fig. 11. Spatial distributions of turbulent kinetic energy (TKE) in the cross-shore direction. 
2

3

4769

5

6

7

8

9

10

11

12

13

14

15

16

17

18

19

20

21

22

23

24770

25

26

27771 28

29772

30

31

32

33

34

35

36

37

38

39

40

41

42

43

44

45

46

47

48

49

50

51

52

53

54

55

56

57

58

59

60

61

62

63

64

65

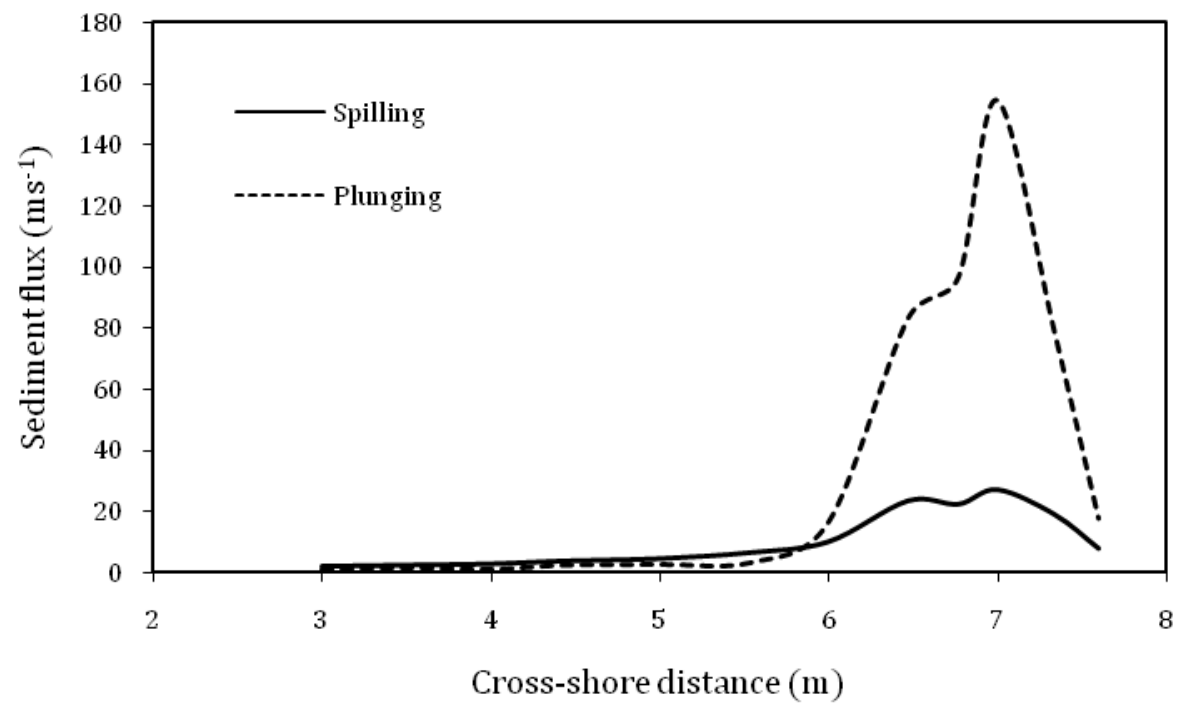

Fig. 12. Spatial distributions of sediment flux in the cross-shore direction under spilling and plunging breakers. 


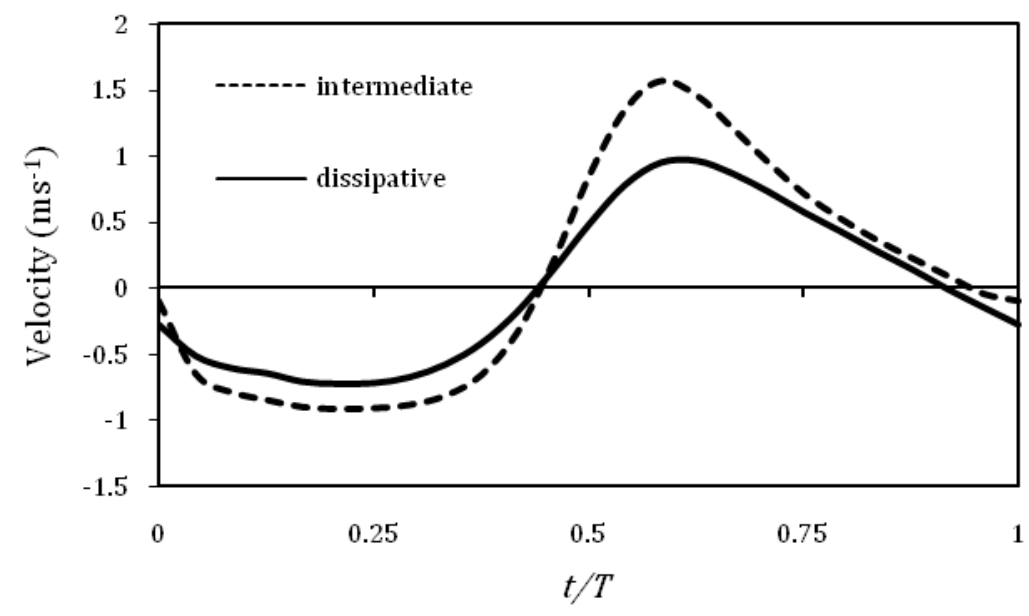

(a)

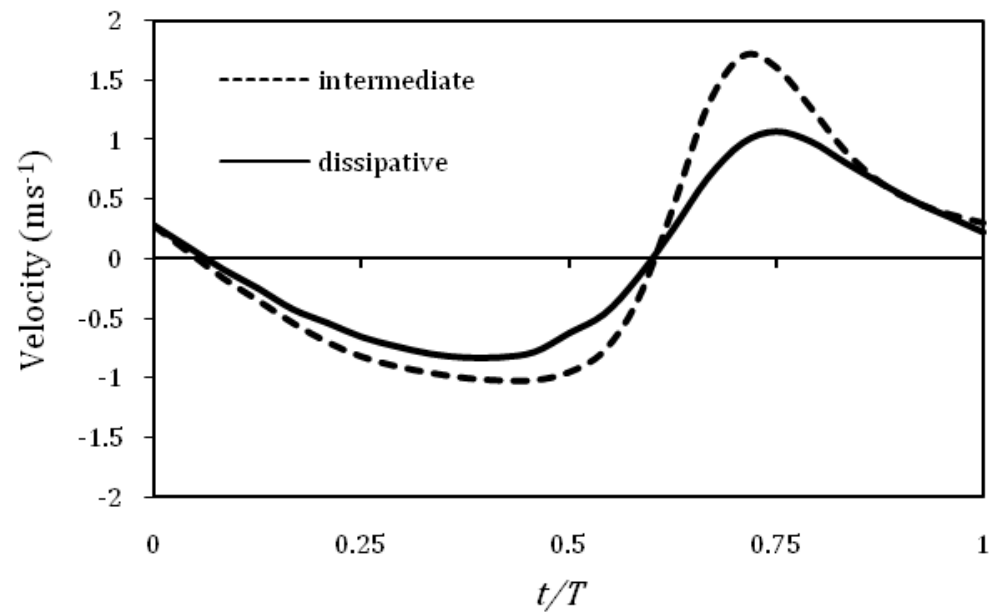

(b) 


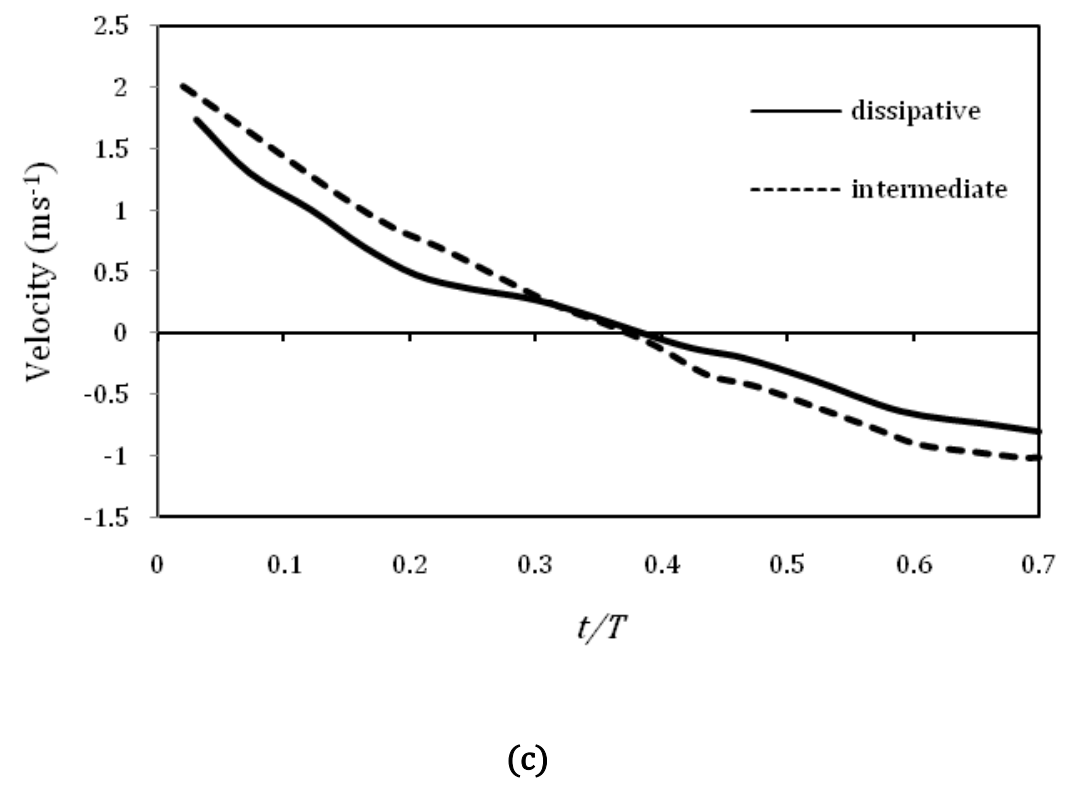

Fig. 13. Temporal variation of velocity for different wave heights in the surf zone: $x=$ (a) 5 and (b) $5.6 \mathrm{~m}$; and swash zone: (c) $x=7.6 \mathrm{~m}$. 